\title{
KNOWLEDGE, ATTITUDE AND PERCEPTION ABOUT STDS INCLUDING HIV INFECTION AMONG ADOLESCENT GIRLS IN INDORE
}

\author{
Vaishali Jain', Sonal Jain², Chandraprabha Jain ${ }^{3}$
}

${ }^{1}$ Consultant, Department of Obstetrics and Gynaecology, Mahaveer Hospital, Indore. ${ }^{2}$ Consultant, Department of Obstetrics and Gynaecology, Mahaveer Hospital, Indore. ${ }^{3}$ Consultant, Department of Obstetrics and Gynaecology, Mahaveer Hospital, Indore.

\begin{tabular}{l}
\hline ABSTRACT \\
\hline BACKGROUND \\
The present study was undertaken to assess the knowledge, attitude and perception about STDs including HIV infection among \\
1000 adolescent school girls in Indore.
\end{tabular}

\section{MATERIALS AND METHODS}

Based on a predesigned, pretested and structured questionnaire, STD score was calculated for every girl. Effect of factors such as age, mother's education, type of family and type of school on STD score was calculated.

\section{RESULTS}

Majority of girls belonged to mid-adolescent group, i.e. 86.6\%, 66\% belonged to English medium private school and only $34 \%$ from Hindi medium government school. Majority of girls lived in nuclear family (58.7\%); 41\% girls had average STD score, $15.5 \%$ had poor score. Only $43.5 \%$ had good score. Late adolescent had a good score as compared to early and mid-adolescent. Girls whose mothers were Graduate and Post-Graduate scored better. Girls in English medium private school scored better. Most important source of information was television (29.2\%) followed by mother (15.3\%).

\section{KEYWORDS}

STDs, HIV, Adolescent Girls, Knowledge, Attitude and Perception.

HOW TO CITE THIS ARTICLE: Jain V, Jain S, Jain C. Knowledge, attitude and perception about STDs including HIV infection among adolescent girls in Indore. J. Evolution Med. Dent. Sci. 2016;5(72):5307-5310, DOI: 10.14260/jemds/2016/1202

\section{BACKGROUND}

The term adolescent is derived from Latin word "adolescere" meaning "to grow to mature." WHO has defined adolescents as person between 10-19 years of age.[1] They constitute about $18 \%$ of the world population, i.e. about 1.2 billion. ${ }^{[2]}$ About $88 \%$ of them live in the developing countries. India has the largest (243 million) number of adolescents comprising one-fourth of the country's population.[3] Pregnancy and Sexually Transmitted Diseases (STDs) including HIV infection constitute important preventable health problems during adolescents. Half of new HIV infection occur among persons < 25 years of age. ${ }^{[4]}$ Adolescent health and nutrition status has an intergenerational effect, hence it is one of the important stages of life cycle in terms of health interventions.[5,6] But this period is often ignored. ${ }^{[7]}$ Nearly two-thirds of premature death and one-thirds of total disease burden in adults are associated with condition or behaviours that begin in their adolescence or youth including tobacco use, lack of physical activity, unprotected sex, early pregnancy and child birth, HIV and other STDs, malnutrition, substance abuse and injuries. ${ }^{[8]}$ Modernisation increasing impact of media, decline of parental authority and increasing gender equality has given rise to a culture that makes sexual activity more appealing and

Financial or Other, Competing Interest: None.

Submission 09-06-2016, Peer Review 03-07-2016,

Acceptance 09-07-2016, Published 08-09-2016.

Corresponding Author:

Dr. Vaishali Jain,

Mahaveer Hospital,

Footi Kothi Square,

Indore, Madhya Pradesh.

E-mail:dr_vaishalijain@yahoo.com

DOI: $10.14260 /$ jemds/2016/1202 acceptable to adolescent without putting much weight or responsibility on sexual behaviour. They face significant risks and are vulnerable to unplanned pregnancy and STDs, a crucial step in order to avoid above problems is to equip young people with proper sexual and reproductive health information (Such as reproductive biology, contraceptive methods and how STDs are contracted, treated and prevented and skills such as how to manage sexual relationships). Parents and teachers, however, avoid any mention to this information with children because it is still regarded as taboo subject in Indian society and secondly they themselves lack scientific knowledge about it. Against this background, present study attempts to assess awareness among school going adolescents girls on STDs including HIV/AIDS.

\section{AIMS AND OBJECTIVES}

To assess the knowledge of adolescent girls about STDs including HIV and to study factors, which influence level of awareness among these girls.

\section{MATERIAL AND METHODS}

A community-based cross-sectional study was carried out between Sep 2007 - 2009 in Dept. of Obstetrics and Gynaecology, MGMMC, Indore (MP). Two Hindi medium government schools, i.e. Shaskiya Ahilya Ashram Avam Chandravati Kanya Ucch Mahavidhyalay No. 1 and Shaskiya Malaw Kanya Ucchatar Madhyamik Vidhyalay and one English medium private school i.e. St. Raphael's Girls higher secondary school were randomly selected for the study. All were exclusively girls schools. After designing the study questionnaire, the approval of research and Ethics Committee of the hospital was sought and obtained. It was given to 1000 
female students in three secondary schools in Indore city. The school authorities were approached and consent duly obtained.

The investigator initially addressed all participants emphasised the objectives of the study, and assured them of the strict confidentiality of their responses. They were also urged to avoid discussing the question among themselves while completing the questionnaire. It consisted of two sections. First section consisted of questions regarding general information of the students, i.e. age, religion, type of school, class in which student was studying and mother's educational status. Second section consisted of question regarding STDs including HIV and source of information. Each session consisted of 40 students and each session took about 1 hour. In the first forty minutes students were asked to attempt the questionnaire. After collecting the questionnaire, a lecture was delivered addressing all the questions and then another 10 mins. were devoted to open discussion and doubts of students were cleared. According to responses of students, each student was given a score of poor, average or good. Hence, STD score for each student was obtained. Factors which influence STD score were evaluated.

\section{RESULTS}

Table 1 show the demographic profile of the study population. In this study, majority of girls belonged to the mid-adolescent age group, i.e. $86.6 \%$.

Table 2 shows that $66 \%$ were from private English medium school; $34 \%$ were from government Hindi medium school.

Table 3 shows that $41 \%$ girls had average STD score, $15.5 \%$ had poor score. Only $43.5 \%$ had good score.

\section{Factors affecting STD Score}

Age Table No. 4 shows in early adolescents most had poor score, i.e. $69.7 \%, 20.9 \%$ had average score.

In mid-adolescents, most had average $(40.4 \%)$ or good score (45.5\%). Only $13.9 \%$ had poor score.

In late adolescents, most had either average (56\%) or good score (39.5\%), only $4.3 \%$ had poor score.

\section{Mother's Education (Table 5)}

Girls whose mothers were illiterate or education up to $5^{\text {th }}$ mostly had either poor (43.1\%) and $44.1 \%$ respectively or average score (24.1\% and $33.7 \%$ respectively).

Those girls whose mothers were educated up to graduation/post-graduation had either average score $(47.4 \%$ and $41.8 \%$ respectively) or good score ( 48.2 and $48.7 \%$ ).

\section{Type of Family (Table 6)}

In nuclear family, girls had good score in $51.9 \%$ cases and poor score in $(11.4 \%)$.

In joint family girls having poor score were $21.3 \%$ and good score were only $31.3 \%$. Thus, we find girls living in nuclear family had greater awareness.

\section{Medium (Table 7)}

In Hindi medium girls having poor, average and good scores were $32.3 \%, 33.8$ and $33.7 \%$ respectively.

In English medium girls, majority had either average or good score, i.e. $44.6 \%$ or $48.3 \%$ respectively; $6.8 \%$ had poor score.
Table 8 shows most important source of information was television $29.2 \%$ followed by parents $15.3 \%$, books $11.5 \%$ and newspaper $10.7 \%$ friends and siblings constituted source of information $48.7 \%$ and $3.4 \%$ respectively; $21.2 \%$ opted for other options.

\begin{tabular}{|c|c|c|}
\hline Age (Years) & Total & Percentage \\
\hline Early Adolescent & 43 & 4.3 \\
\hline Mid-Adolescent & 866 & 86.6 \\
\hline Late Adolescent & 91 & 9.1 \\
\hline Grand Total & $\mathbf{1 0 0 0}$ & $\mathbf{1 0 0}$ \\
\hline Table 1: Age Wise Distribution of Girls \\
\hline
\end{tabular}

\begin{tabular}{|c|c|c|}
\hline Type of School & Total & Percentage \\
\hline Hindi medium government & 340 & 34 \\
\hline English medium private & 660 & 66 \\
\hline Grand Total Table 2 & $\mathbf{1 0 0 0}$ & $\mathbf{1 0 0}$ \\
\hline \multicolumn{2}{|c}{} \\
\hline
\end{tabular}

\begin{tabular}{|c|c|c|}
\hline STD Score & Total & Percentage \\
\hline Poor & 155 & 15.5 \\
\hline Average & 410 & 41.0 \\
\hline Good & 435 & 43.5 \\
\hline Grand Total & $\mathbf{1 0 0 0}$ & $\mathbf{1 0 0}$ \\
\hline \multicolumn{3}{|c|}{ Table 3: STD Score } \\
\hline
\end{tabular}

\begin{tabular}{|c|c|c|c|c|}
\hline \multirow{2}{*}{$\begin{array}{c}\text { Age } \\
\text { Group }\end{array}$} & \multicolumn{4}{|c|}{ STD Score (Percentage) } \\
\cline { 2 - 5 } & Poor & Average & Good & $\begin{array}{c}\text { Grand } \\
\text { Total }\end{array}$ \\
\hline Early & $\begin{array}{c}30 \\
(69.7 \%)\end{array}$ & $9(20.9 \%)$ & $\begin{array}{c}4 \\
(9.3 \%)\end{array}$ & 43 \\
\hline Mid & $\begin{array}{c}121 \\
(13.9 \%)\end{array}$ & $\begin{array}{c}350 \\
(40.4)\end{array}$ & $395(45.5 \%)$ & 866 \\
\hline Late & $\begin{array}{c}4 \\
(4.3 \%)\end{array}$ & $\begin{array}{c}51 \\
(56 \%)\end{array}$ & $\begin{array}{c}36 \\
(39.5 \%)\end{array}$ & 91 \\
\hline $\begin{array}{c}\text { Grand } \\
\text { Total }\end{array}$ & $\mathbf{1 5 5}$ & $\mathbf{4 1 0}$ & $\mathbf{4 3 5}$ & $\mathbf{1 0 0 0}$ \\
\hline \multicolumn{5}{|c|}{ Table 4: Age versus STD Score } \\
\hline
\end{tabular}

\begin{tabular}{|c|c|c|c|c|}
\hline \multirow{2}{*}{$\begin{array}{l}\text { Mother's } \\
\text { Education }\end{array}$} & \multicolumn{4}{|c|}{ STD Score } \\
\hline & Poor & Average & Good & $\begin{array}{l}\text { Grand } \\
\text { Total }\end{array}$ \\
\hline Illiterate & $50(43.1 \%)$ & $28(24.1 \%)$ & $38(32.7 \%)$ & 116 \\
\hline Primary & $38(44.1 \%)$ & $29(33.7 \%)$ & $19(22 \%)$ & 86 \\
\hline Middle & $27(27 \%)$ & $51(51 \%)$ & $22(22 \%)$ & 100 \\
\hline $\begin{array}{c}\text { Higher } \\
\text { secondary }\end{array}$ & $5(4 \%)$ & $42(33.6 \%)$ & $78(62.4 \%)$ & 125 \\
\hline Graduate & $15(4.1 \%)$ & $170(47.4 \%)$ & $173(48.2 \%)$ & 358 \\
\hline $\begin{array}{c}\text { Post } \\
\text { graduate }\end{array}$ & $20(9.3 \%)$ & $90(41.8 \%)$ & $105(48.7 \%)$ & 215 \\
\hline $\begin{array}{c}\text { Grand } \\
\text { Total }\end{array}$ & 155 & 410 & 435 & 1000 \\
\hline
\end{tabular}

\begin{tabular}{|c|c|c|c|c|}
\hline \multirow{2}{*}{$\begin{array}{l}\text { Type of } \\
\text { Family }\end{array}$} & \multicolumn{4}{|c|}{ STD Score (Percentage) } \\
\hline & Poor & Average & Good & $\begin{array}{c}\text { Grand } \\
\text { Total }\end{array}$ \\
\hline Nuclear & $67(11.4 \%)$ & $215(36.6 \%)$ & $305(51.9 \%)$ & 587 \\
\hline Joint & $88(21.3 \%)$ & $195(47.2 \%)$ & $130(31.3 \%)$ & 413 \\
\hline $\begin{array}{c}\text { Grand } \\
\text { Total }\end{array}$ & 155 & 410 & 435 & 1000 \\
\hline
\end{tabular}




\begin{tabular}{|c|c|c|c|c|}
\hline \multirow{2}{*}{ Medium } & \multicolumn{4}{|c|}{ STD Score } \\
\cline { 2 - 5 } & Poor & Average & Good & $\begin{array}{c}\text { Grand } \\
\text { Total }\end{array}$ \\
\hline Hindi & $110(32.3 \%)$ & $\begin{array}{c}115 \\
(33.8 \%)\end{array}$ & $115(33.7 \%)$ & 340 \\
\hline English & $45(6.8 \%)$ & $295(44.6 \%)$ & $320(48.4 \%)$ & 660 \\
\hline $\begin{array}{c}\text { Grand } \\
\text { Total }\end{array}$ & 115 & 410 & 435 & 1000 \\
\hline \multicolumn{5}{|c|}{ Table 7: Medium to STD Score } \\
\hline
\end{tabular}

\begin{tabular}{|c|c|c|}
\hline Source of Information & Total & Percentage \\
\hline Mother & 153 & 15.3 \\
\hline Friends & 87 & 8.7 \\
\hline Brother/Sister & 34 & 3.4 \\
\hline Television & 292 & 29.2 \\
\hline News Paper & 107 & 10.7 \\
\hline Books & 115 & 11.5 \\
\hline Others & 212 & 21.2 \\
\hline Grand Total & $\mathbf{1 0 0 0}$ & $\mathbf{1 0 0}$ \\
\hline \multicolumn{2}{|l}{ Table 8: Source of Information } \\
\hline
\end{tabular}

\section{DISCUSSION}

\section{Knowledge about STD'S}

In our study most of girls had a score of either average or good STD score, i.e. $41 \%$ and $43.5 \%, 15.5 \%$ had poor score.

Gupta Sadhna, Sinha Achala in their study found that majority of girls have only incomplete knowledge on STD/AIDS. Major source of information was television in both groups. ${ }^{(9)}$

Nidhi Kotwal, Neelima Gupta and Rashi Gupta, in their study found that the areas where both school going girls and school dropout girls scored low were clinical symptoms and biological symptoms of AIDS and relationship between AIDS/HIV/STDS.(10)

Hassan MK, Jayaswal M, Hassan P (2003), reproductive health awareness in rural tribal female adolescents revealed that the awareness was distressingly low.(11)

Low level of awareness was also found in study done in Rajasthan.[12] According to NFHS-3 (2005-06), 46\% women and $81 \%$ men were aware of AIDS.[13] In studies by Anjali Singh in Gujarat and Calcutta, awareness was reported to be only $35 \%$ and $13.5 \%$ respectively.[14,15]

However, in a study done in Kerala reporting $100 \%$ awareness of AIDS could be explained on the basis of older age of study sample (18-22 yrs.) and residence in state with maximum literacy.(16)

In our study, it was found that awareness increased with age and mother's educational status, girls studying in English medium private schools and in nuclear families were found to be more aware.

In a study done by Gupta $M$ et al in 2011, it was found that predictors observed to be significant for awareness of ARSH services were age of adolescents, education of father, family income, geographical area and educational status of adolescents.[17]

\section{Source of Information}

In our study, most important source of information came out to be television $(29.2 \%)$ followed by parents $15.3 \%$, books $11.5 \%$ and newspaper $10.7 \%$. Friends and siblings constituted source of information in $8.7 \%$ and $3.4 \%$ respectively; $21.2 \%$ opted for other options.

Chhabra S in his prospective study of school girls showed that knowledge sources were mainly literature and movies (77.9\%).[18]

Singh MM et al in his study found that major sources of information were television $73.1 \%$, radio $37.1 \%$ and parents (36.1\%). Girls preferred to consult parents (49.2\%) and doctors $(44.6 \%)$ for help at times of having reproductive health problems.

Diane Kittredge (2005) in his study found that most adolescents $(70 \%)$ had heard of family planning practices mostly from TV and radio.

\section{CONCLUSION}

Adolescents represent approximately one-fifth of the total population of which $85 \%$ are living in developing countries.

This group is not adequately prepared for reproductive and sexual life, since these group of people lack basic information about their body, sexuality and contraception and STD's.[19]

In societies like India where talking about sex is a taboo, the adolescents really find it difficult to acquire correct scientific knowledge about it.

A majority of victims of HIV/AIDS are young and under the age of 30 , of which about $30 \%$ are in the sexually active phase of life. It is therefore essential to catch them young, impart them knowledge on adolescent sexual health, STDs, HIV/AIDS before they indulge in high-risk behaviour. They are vulnerable to practicing unsafe sex, hence this group should be the target for imparting health education on safe sex.

The sex education should be an integral part of the learning process beginning in the childhood and continuing into adult life. It should encourage exploration of values and moral values, consideration of sexuality and personal relationships and development of communication and decision making skills. It should foster self-esteem, selfawareness and a sense of moral responsibility and skills to avoid and resist sexual experience.

\section{REFERENCES}

1. World Health Organization. The reproductive health of adolescence, strategy for action. A joint WHO/UNFA/UNFPA/ UNICEF statement. Geneva: WHO 1989:1.

2. Demographic trend for adolescent: ten key facts. Available from: http: //www.unilef.org/SOWC 2011/pdfs/Demographic trends.

3. Strategic directions for improving adolescent health in south east Asia. World Health organization 2011. Available from : http://www.searo.who.int/link files / publications_SE-CAH-04.

4. Government of India. Sample registration system statistical report 2003, Report No:2, 2005.

5. The State of world's children. Adolescence: an age of opportunity united nations international children's emergency fund (UNICEF) 2011. Available from http://www.unicef org/SOWC 2011/pdfs/ SOWC-2011Main - Report_EN 02092011.

6. Sawyer SM, Afifi RA, Bearinger LH, et al. Adolescence: a foundation for future health. Lancet 2012;379(9826):1630-40. 
7. Progress for children: a report card of adolescents. UNICEF 2012. Available from: http:// www.unicef.org/media files PFC 2012- A Report card on adolescents.

8. Young people health risks and solution: Available from: http://www.who.int./mediacentre/factsheets/fs345/e n/indexhtml.

9. Sadhna G, Achal S. Awareness about reproduction and adolescent changes among school girls of different socioeconomic status. J Obstet Gynecol India 2006;56(4):324-28.

10. Kotwal N, Gupta N, Gupta R. Awareness of reproductive health among rural adolescent girls (A comparative study of school going girls and dropout girls of Jammu). Stud home Comm. Sci 2008;2(2):149-54.

11. Hassan MK, Jayaswal M, Hassan P. Reproductive health awareness in rural tribal female adolescents. Ranchi, India, Ranchi University 2003:16.

12. Bagla J, Mayangar A, Bagla R, et al. Knowledge, attitude, and perception of adolescents regarding reproductive health and HIV/AIDS in Rajasthan. Indian J child health 2014;1(3):122-7.

13. NFHS 3 - India (Rajasthan ) HIV/AIDS report, 2005-06, Available from http//www.nfhs india.org.
14. Singh A, Jain S. Awareness of HIV/ AIDS among school in Banaskantha of Gujarat. Health Popul Perspect Issues 2009;32(2):59-65.

15. Ram R, Roy M, Dhar G, et al. A study on awareness of AIDS among school children and teachers of of higher secondary schools in north Calcutta. Indian Journal of Public Health 2001;45(1):27-30.

16. Lal SS, Vasan RS, Sarma PS, et al. Knowledge and attitude of college students in Kerala towards HIV/AIDS, sexually transmitted diseases and sexuality. Nad med J India 2000;13(5):231-6.

17. Gupta $M$, Bhatnagar $N$, Bahugana $P$. Inequity in awareness and utilization of adolescent reproductive and sexual health services in union territory Chandigarh, north India. India J public health 2015;59(1):9-17.

18. Chhabra S. A step towards helping mothers with unwanted pregnancies. Indian J matern Child Health 1992;3(2):41-2.

19. Singh MM, Devi R, Gupta SS. Awareness and health seeking behavior of rural adolescent school girls on menstrual and reproductive health problems. Indian Journal of medical sciences 1999;53(10):439-43.

20. WHO. AIDS Images of epidemic. Geneva: WHO 1994:1922. 